\title{
A profile of body mass index in a large rural Victorian obstetric cohort
}

\section{Chris E Cunningham MSc, BLit, BA, PhD Candidate, Rura Health Academic Centre \\ Glyn R Teale MRCP, MRCOG, FRANZCOG Associate Professor NorthWest Academic Centre $^{2}$}

IUniversity of Melbourne, Shepparton, VIC 2 University of Melbourne, Melbourne, VIC

chrisecl@ bigpond.net.au

MJA 2013; 198: 39-42 doi: 10.5694/mjal2.11033
E xtensive research has identified overweight and obesity as significant risks for poor obstetric and perinatal outcomes. ${ }^{1-5}$ It is widely accepted that increased adiposity increases the likelihood of a range of adverse health conditions affecting pregnancy, such as hypertension, thromboembolism, pre-eclampsia and gestational diabetes. ${ }^{6-8}$ Overweight and obesity are believed to impact on the birth process with increased rates of inductions, operative deliveries and technical problems with anaesthetics, ${ }^{1,9}$ as well as increased rates of wound breakdown in mothers and longer lengths of hospital stay. ${ }^{10}$ Obesity and overweight can also impact on fetal and neonatal health, with increased incidence of abnormal birthweight (large or small for gestational age), birth trauma, shoulder dystocia, fetal distress and increased perinatal mortality. ${ }^{1,10-13}$

Australian studies have reported the prevalence of overweight and obesity in urban obstetric populations as $18 \%$ in Perth and 34\% Brisbane. ${ }^{1,2,12}$ Analysis of a state-wide database of South Australian women reported overweight and obesity prevalence rates of $50.0 \%$ overall and $54.4 \%$ in rural areas. ${ }^{5}$ The present study was initiated as a result of concern about even higher levels of pregnancy overweight and obesity in rural Victoria.

\section{Methods}

\section{Data source}

Goulburn Valley Health (GVH), in north-east Victoria, is a Level 5 provider of maternity services (Department of Health Capability framework for Victorian maternity and newborn services ${ }^{14}$ ), delivering about 1100 births annually. It serves as a referral hospital for up to seven smaller services in the surrounding areas. Obstetric and neonatal data are routinely collected into a Birthing Outcome System (Version 5, MCATS) database, which includes general demographics, height, weight and antenatal

\begin{abstract}
Objectives: To report on the prevalence and implications of overweight and obesity in a rural maternity cohort.

Design, setting and participants: A retrospective 6-year cohort of 6138 pregnancies managed in a rural Victorian maternity service from 1 January 2005 to 31 December 2010.

Main outcome measures: Maternal body mass index (BMI), prevalence of overweight and obesity, prevalence of pregnancy complications and their association with BMI class.

Results: A total of $65.6 \%$ of all women were overweight or obese. Only $32.7 \%$ of the women were of normal/healthy weight; $1.6 \%$ were underweight, 33.0\% were overweight, $18.6 \%$ were obese class I, $8.3 \%$ obese class II and $5.7 \%$ were obese class III. Increased BMI was associated with increased rates of induction of labour, gestational diabetes mellitus, pregnancy-induced hypertension, operative vaginal deliveries, caesarean sections, invasive fetal monitoring, increased gestational age at delivery, increased birth weight, and increased maternal length of stay $(P<0.01$ for all $)$. Analysed separately, $60.5 \%$ of firsttime mothers were overweight or obese.

Conclusions: Almost two-thirds of this rural maternity cohort were overweight or obese; twice the level reported from metropolitan centres and higher than other Australian reports. The associations with complications are similar to those reported previously. This high rate of maternal overweight and obesity may have implications for rural maternity funding, outcomes and perinatal mortality rates.
\end{abstract}

information, and all data pertaining to the delivery and immediate postnatal period and neonatal outcomes. Body mass index (BMI) is calculated using the height and weight measured during the first antenatal visit (weight $[\mathrm{kg}]$ divided by height squared $\left.\left[\mathrm{m}^{2}\right]\right)$.

\section{Sample}

The data were reviewed for all 6796 mothers giving birth from 1 January 2005 to 31 December 2010. There were 100 multiple births and 378 unbooked deliveries, which were excluded, leaving 6318 in the sample. Of these, 180 were excluded because the mothers' height and/or weight were not recorded, and as these missing values represented $2.8 \%$ of the dataset, no analyses were conducted on differences. The BMI for the remaining mothers $(n=6138)$ was calculated $\left(\mathrm{kg} / \mathrm{m}^{2}\right)$ and classified according to the classifications recommended by the World Health Organization, with "underweight" defined as $\mathrm{BMI}<18.5 \mathrm{~kg} / \mathrm{m}^{2}$, "normal" defined as BMI 18.5-24.9kg/m², "overweight" as BMI $25.0-29.9 \mathrm{~kg} / \mathrm{m}^{2}$, "obese I" as BMI $30.0-34.9 \mathrm{~kg} / \mathrm{m}^{2}$, "obese II" as BMI $35.0-39.9 \mathrm{~kg} / \mathrm{m}^{2}$ and "obese III" as $\mathrm{BMI} \geqslant 40.0 \mathrm{~kg} / \mathrm{m}^{2}{ }^{15}$ Incidence of over- weight and obesity was established for the whole group, multiparae $(n=3893)$, nulliparae $(n=2245)$, and those weighed before and after 13 weeks' gestation.

Characteristics of the mother, neonate and delivery method for each BMI group were explored for all cases. Maternal age was calculated as the age at the time of delivery. The mother's Aboriginal and Torres Strait Islander status was used to determine Aboriginality, and country of origin was recoded to "Australia" or "other". Requirement for an interpreter was also reported. A woman was classified as a smoker if she had smoked at any time during the pregnancy. Alcohol intake related to any alcohol intake at any time during pregnancy. "Depression" was reported for any recorded history of depression. Pregnancyrelated hypertension was reported if the clinical notes recorded pregnancyinduced hypertension and/or preeclampsia. The length of stay was calculated from the date of delivery until the date of maternal discharge. The upper quartile length of stay was calculated as a cut-point for the derived variable "longer length of stay". 


\begin{tabular}{|c|c|c|c|c|c|c|c|}
\hline \multirow[b]{2}{*}{ Characteristics } & \multicolumn{7}{|c|}{ BMI class $\left(\mathrm{kg} / \mathrm{m}^{2}\right)$} \\
\hline & $\begin{array}{c}\text { Underweight } \\
(<18.5) \\
n=101(1.6 \%)\end{array}$ & $\begin{array}{c}\text { Normal } \\
(18.5-24.9) \\
n=2010(32.7 \%)\end{array}$ & $\begin{array}{c}\text { Overweight } \\
(25.0-29.9) \\
n=2027(33.0 \%)\end{array}$ & $\begin{array}{c}\text { Obese I } \\
(30.0-34.9) \\
n=1141(18.6 \%)\end{array}$ & $\begin{array}{c}\text { Obese II } \\
(35.0-39.9) \\
n=509(8.3 \%)\end{array}$ & $\begin{array}{c}\text { Obese III } \\
(\geqslant 40.0) \\
n=350(5.7 \%)\end{array}$ & $P$ \\
\hline Mean age in years (SD) & $25.6(6.0)$ & $27.9(5.8)$ & $29.3(5.7)$ & $29.1(5.7)$ & $29.4(5.6)$ & $29.8(5.5)$ & $<0.001$ \\
\hline \multicolumn{8}{|l|}{ Parity } \\
\hline 0 & $48(47.5 \%)$ & $838(41.7 \%)$ & $729(36.0 \%)$ & $377(33.0 \%)$ & $165(32.4 \%)$ & $88(25.1 \%)$ & \\
\hline 1 & $27(26.7 \%)$ & $664(33.0 \%)$ & $665(32.8 \%)$ & $372(32.6 \%)$ & $163(32.0 \%)$ & $112(32 \%)$ & \\
\hline 2 & $16(15.8 \%)$ & $300(14.9 \%)$ & $351(17.3 \%)$ & $193(16.9 \%)$ & $91(17.9 \%)$ & $75(21.4 \%)$ & \\
\hline 3 & $6(5.9 \%)$ & $123(6.1 \%)$ & $159(7.8 \%)$ & $102(8.9 \%)$ & $46(9.0 \%)$ & $48(13.7 \%)$ & \\
\hline$\geqslant 4$ & $4(4.0 \%)$ & $85(4.2 \%)$ & $123(6.1 \%)$ & $97(8.5 \%)$ & $44(8.6 \%)$ & $27(7.7 \%)$ & \\
\hline Aboriginal or Torres Strait Islander (mother) & $10(9.9 \%)$ & $99(4.9 \%)$ & $81(4.0 \%)$ & $82(7.2 \%)$ & $28(5.5 \%)$ & $32(9.1 \%)$ & 0.003 \\
\hline Australian born & $80(79.2 \%)$ & $1667(82.9 \%)$ & $1668(82.3 \%)$ & $974(85.4 \%)$ & $461(90.6 \%)$ & $312(89.1 \%)$ & $<0.001$ \\
\hline Interpreter required & $5(5.0 \%)$ & $126(6.3 \%)$ & $140(6.9 \%)$ & $86(7.5 \%)$ & $22(4.3 \%)$ & $19(5.4 \%)$ & 0.43 \\
\hline Smoker at any time during pregnancy & $51(50.5 \%)$ & $653(32.5 \%)$ & $573(28.3 \%)$ & $343(30.1 \%)$ & $176(34.6 \%)$ & $110(31.4 \%)$ & 0.34 \\
\hline Drinks alcohol at any time during pregnancy & $7(6.9 \%)$ & $249(12.4 \%)$ & $336(16.6 \%)$ & $144(12.6 \%)$ & $73(14.3 \%)$ & $49(14.0 \%)$ & 0.29 \\
\hline Insurance status, private & $7(6.9 \%)$ & $306(15.2 \%)$ & $415(20.5 \%)$ & $180(15.8 \%)$ & $83(16.3 \%)$ & $47(13.4 \%)$ & 0.96 \\
\hline Hypertensive disorders of pregnancy* & $1(1.0 \%)$ & $23(1.1 \%)$ & $27(1.3 \%)$ & $30(2.6 \%)$ & $12(2.4 \%)$ & $23(6.6 \%)$ & $<0.001$ \\
\hline Gestational diabetes & $3(3.0 \%)$ & $57(2.8 \%)$ & $85(4.2 \%)$ & $75(6.6 \%)$ & $50(9.8 \%)$ & $48(13.7 \%)$ & $<0.001$ \\
\hline Depression (past history or current) & $18(17.8 \%)$ & $202(10.0 \%)$ & $198(9.8 \%)$ & $124(10.9 \%)$ & $51(10.0 \%)$ & $45(12.9 \%)$ & 0.49 \\
\hline Median length of stay in days (IQR) & $3(2-3)$ & $3(2-4)$ & $3(2-4)$ & $3(2-4)$ & $3(2-4)$ & $3(2-4)$ & 0.008 \\
\hline Induction of labour & $11(10.9 \%)$ & $369(18.4 \%)$ & $501(24.7 \%)$ & $324(28.4 \%)$ & $148(29.1 \%)$ & $113(32.3 \%)$ & $<0.001$ \\
\hline Normal vaginal delivery & $77(76.2 \%)$ & $1437(71.5 \%)$ & $1384(68.3 \%)$ & $744(65.2 \%)$ & $311(61.1 \%)$ & $201(57.4$ & $<0.001$ \\
\hline Instrument assisted vaginal delivery & $8(7.9 \%)$ & $196(9.8 \%)$ & $162(8.0 \%)$ & $84(7.4 \%)$ & $22(4.3 \%)$ & $19(5.4 \%)$ & $<0.001$ \\
\hline Emergency caesarean section & $8(7.9 \%)$ & $172(8.6 \%)$ & $232(11.4 \%)$ & $161(14.1 \%)$ & $75(14.7 \%)$ & $48(13.7 \%)$ & $<.001$ \\
\hline Elective caesarean section & $6(5.9 \%)$ & $182(9.1 \%)$ & $224(11.1 \%)$ & $138(12.1 \%)$ & $99(19.5 \%)$ & $80(22.9 \%)$ & $<0.001$ \\
\hline Vaginal birth after caesarean & $2(2.0 \%)$ & $21(1.0 \%)$ & $23(1.1 \%)$ & $14(1.2 \%)$ & $1(0.2 \%)$ & $2(0.6 \%)$ & 0.16 \\
\hline
\end{tabular}

$\mathrm{IQR}=$ interquartile range.

* Significant but small numbers.

Induction included artificial rupture of membranes and/or pharmacological interventions. Gestational age was the reported estimated gestational age at delivery, as determined during antenatal care from the results of ultrasound, known dates and clinical examination. The proportion of smallfor-gestational-age neonates and large-for-gestational-age neonates was calculated for term ( $\geqslant 37$ weeks) deliveries only to minimise the effect of preterm birth. Small for gestational age was defined as a birth weight less than the 10th percentile, and large for gestational age was defined as a birth weight greater than the 90th percentile, adjusted for gestation and gender. ${ }^{16}$ Perinatal death rates did not include women or neonates who were transferred and died elsewhere. Respiratory distress was recorded if specified in the clinical notes. Gestational diabetes was defined in accordance with the Australasian Diabetes in Pregnancy Society guidelines. ${ }^{17}$

For normally distributed data, analysis of variance (ANOVA) or $t$ tests were used. For skewed data, non-parametric tests such as the Cochran-Armitage test for trend, Mann-Whitney $U$ and Kruskal-Wallis tests were used to test difference. Adjusted odds ratios (AORs) were calculated with 95\% CI using logistic regression analyses controlling for maternal age, parity, smoking status and insurance class. The normal BMI class $\left(18.5-24.9 \mathrm{~kg} / \mathrm{m}^{2}\right)$ was used as the reference group for all others. Goodness-of-fit tests were performed and were satisfactory. All statistical analyses were conducted using SPSS (Version 17, IBM).

The Goulburn Valley Health Ethics and Research Committee and the University of Melbourne Human Research Ethics Committee approved this study.

\section{Results}

A total of 6138 women were included in the sample. Of these, $101(1.6 \%)$ were underweight, 2010 (32.7\%) were of normal weight, 2027 (33.0\%) were overweight, $1141(18.6 \%)$ were obese class I, 509 (8.3\%) obese class II and $350(5.7 \%)$ were obese class III. The proportions in each category have been consistent over the period of the study $(P=0.48)$.

Increased BMI was related to increased rates of induction of labour, gestational diabetes mellitus, pregnancy-induced hypertension, operative vaginal deliveries, caesarean sections (both emergency and elective) (Box 1) and internal fetal monitoring (Box 2). Further, it was found that increased BMI was associated with increased gestational age at delivery and increased birth weight for gestation and gender. Underweight BMI was associated with reduced levels of some maternal complications, such as induction of labour and caesarean deliveries, but not operative vaginal deliveries and preterm birth. Underweight women were found to smoke more but drink less alcohol during pregnancy than women of normal weight (Box 1).

The women who were classified obese class I, II or III were more likely to experience pregnancy-induced hypertension in reference to the women of normal weight (AOR, 2.45; 


\begin{tabular}{|c|c|c|c|c|c|c|c|}
\hline \multirow[b]{2}{*}{ Characteristics } & \multicolumn{7}{|c|}{ BMI class $\left(\mathrm{kg} / \mathrm{m}^{2}\right)$} \\
\hline & $\begin{array}{c}\text { Underweight } \\
(<18.5) \\
n=101(1.6 \%)\end{array}$ & $\begin{array}{c}\text { Normal } \\
(18.5-24.9) \\
n=2010(32.7 \%)\end{array}$ & $\begin{array}{c}\text { Overweight } \\
(25.0-29.9) \\
n=2027(33.0 \%)\end{array}$ & $\begin{array}{c}\text { Obese I } \\
(30.0-34.9) \\
n=1141(18.6 \%)\end{array}$ & $\begin{array}{c}\text { Obese II } \\
(35.0-39.9) \\
n=509(8.3 \%)\end{array}$ & $\begin{array}{c}\text { Obese III } \\
(\geqslant 40.0) \\
n=350(5.7 \%)\end{array}$ & $P$ \\
\hline $\begin{array}{l}\text { Internal fetal monitoring (eg, fetal scalp } \\
\text { electrode) }\end{array}$ & $30(29.7 \%)$ & $623(31.0 \%)$ & $604(29.8 \%)$ & $370(32.4 \%)$ & $176(34.6 \%)$ & $131(37.4 \%)$ & 0.004 \\
\hline Fetal scalp lactate testing & 0 & $11(0.5 \%)$ & $18(0.9 \%)$ & $8(0.7 \%)$ & $3(0.6 \%)$ & $3(0.9 \%)$ & 0.52 \\
\hline Male & $54(53.5 \%)$ & $1009(50.2 \%)$ & $1084(53.5 \%)$ & $574(50.3 \%)$ & $276(54.2 \%)$ & $183(52.3 \%)$ & 0.43 \\
\hline Mean gestational age at delivery in weeks (SD) & $38.6(2.4 \%)$ & $39.2(1.9 \%)$ & $39.4(1.9 \%)$ & $39.4(1.8 \%)$ & $39.2(2.2 \%)$ & $39.3(1.7 \%)$ & $<0.001$ \\
\hline Macrosomia $>4000 \mathrm{~g}$ & $2(2.0 \%)$ & $169(8.4 \%)$ & $289(14.3 \%)$ & $210(18.4 \%)$ & $122(24.0 \%)$ & $78(22.3 \%)$ & $<0.001$ \\
\hline Macrosomia > $4500 \mathrm{~g}$ & 0 & $32(1.6 \%)$ & $46(2.3 \%)$ & $42(3.7 \%)$ & $32(6.3 \%)$ & $21(6 \%)$ & $<0.001$ \\
\hline SGA* & $24(23.8 \%)$ & $224(11.1 \%)$ & $174(8.6 \%)$ & $84(7.4 \%)$ & $25(4.9 \%)$ & $26(7.4 \%)$ & $<0.001$ \\
\hline LGA* & $2(2.0 \%)$ & $166(8.3 \%)$ & $298(14.7 \%)$ & $211(18.5 \%)$ & $133(26.1 \%)$ & $87(24.9 \%)$ & $<0.001$ \\
\hline Phototherapy & $4(4.0 \%)$ & $65(3.2 \%)$ & $72(3.6 \%)$ & $40(3.5 \%)$ & $25(4.9 \%)$ & $14(4 \%)$ & 0.18 \\
\hline Perinatal death $^{\dagger}$ & $1(1.0 \%)$ & $14(0.7 \%)$ & $12(0.6 \%)$ & $8(0.7 \%)$ & $4(0.8 \%)$ & $3(0.9 \%)$ & 0.62 \\
\hline Respiratory distress & $4(4.0 \%)$ & $78(3.9 \%)$ & $88(4.3 \%)$ & $52(4.6 \%)$ & $26(5.1 \%)$ & $18(5.1 \%)$ & 0.05 \\
\hline$<37$ weeks' gestation & $14(13.9 \%)$ & $118(5.9 \%)$ & $90(4.4 \%)$ & $45(3.9 \%)$ & $31(6.1 \%)$ & $15(4.3 \%)$ & 0.028 \\
\hline Transfer to neonatal intensive care & $1(1.0 \%)$ & $20(1.0 \%)$ & $23(1.1 \%)$ & $12(1.1 \%)$ & $5(1.0 \%)$ & $3(0.9 \%)$ & 0.88 \\
\hline
\end{tabular}

95\% CI, 1.42-4.26 for obese class I; $\mathrm{AOR}, 2.22$; 95\% CI, 1.09-4.50 for obese class II; AOR, 6.70; 95\% CI, 3.69-12.17 for obese class III). Women classified as obese were also more likely to experience gestational diabetes, have neonates with a birthweight of greater than $4500 \mathrm{~g}$ and stay in hospital for longer than the 75th percentile (Box 3).

Women with a BMI class of overweight or higher were more likely to have induced labour and require an emergency caesarean delivery, compared with the normal BMI class. Underweight women were more likely to deliver before 37 weeks
(AOR, 2.40; 95\% CI, 1.32-4.37), but obese class I women were less likely to deliver before 37 weeks than women of normal weight (AOR, 0.66; 95\% CI, 0.47-0.95).

Internal fetal monitoring, such as fetal scalp electrode, was more likely in all obese classes, with the likelihood increasing with the level of obesity (AOR, 1.18; 95\% CI, 1.011.39 for class I; AOR, 1.31; 95\% CI, 1.06-1.62 for class II; and AOR, 1.64; 95\% CI, 1.29-2.10 for class III) relative to the normal weight group (Box 3).

For nulliparae only $(n=2245)$, there was an overall prevalence of over- weight and obesity of $60.5 \%$ (1359), with $32.5 \%$ (729) overweight, $16.8 \%$ (377) obese class I, 7.3\% (165) obese class II and 3.9\% (88) class III.

Of the total sample, there were $1007(16.4 \%)$ women with a recorded BMI from < 13 weeks' gestation, and of these, $61.0 \%$ (615) were overweight or obese. Similarly, of the 3119 women with a BMI recorded before 20 weeks' gestation, 1918 (61.5\%) were overweight or obese.

\section{Discussion}

The rates of overweight and obesity in this rural obstetric population are

3 Adjusted odds ratios* $(95 \% \mathrm{Cl})$ for complications in 6138 mothers and their neonates in a rural Victorian maternity cohort by mother's body mass index (BMI) class

\begin{tabular}{|c|c|c|c|c|c|}
\hline & \multicolumn{5}{|c|}{ BMI class $\left(\mathrm{kg} / \mathrm{m}^{2}\right)^{\dagger}$} \\
\hline & $\begin{array}{c}\text { Underweight } \\
(<18.5) \\
n=101(1.6 \%)\end{array}$ & $\begin{array}{c}\text { Overweight } \\
(25.0-29.9) \\
n=2027(33.0 \%)\end{array}$ & $\begin{array}{c}\text { Obese I } \\
(30.0-34.9) \\
n=1141(18.6 \%)\end{array}$ & $\begin{array}{c}\text { Obese II } \\
(35.0-39.9) \\
n=509(8.3 \%)\end{array}$ & $\begin{array}{c}\text { Obese III } \\
(\geqslant 40.0) \\
n=350(5.7 \%)\end{array}$ \\
\hline \multicolumn{6}{|l|}{ Complications } \\
\hline Gestational diabetes & $1.34(0.46-4.39)$ & $1.32(0.94-1.87)$ & $2.19(1.53-3.13)$ & $3.34(2.24-4.98)$ & $4.81(3.19-7.25)$ \\
\hline Pregnancy-related hypertension & $0.95(0.13-7.12)$ & $1.17(0.67-2.06)$ & $2.45(1.42-4.26)$ & $2.22(1.09-4.50)$ & $6.70(3.69-12.17)$ \\
\hline Induction of labour & $0.57(0.30-1.07)$ & $1.46(1.25-1.70)$ & $1.80(1.51-2.14)$ & $1.86(1.49-2.32)$ & $2.21(1.72-2.85)$ \\
\hline Maternal length of stay $>4$ days $s^{\ddagger}$ & $0.59(0.29-1.19)$ & $1.10(0.92-1.32)$ & $1.42(1.16-1.74)$ & $1.60(1.23-2.07)$ & $1.94(1.45-2.60)$ \\
\hline Emergency caesarean & $1.04(0.49-2.20)$ & $1.40(1.13-1.73)$ & $1.95(1.54-2.46)$ & $2.03(1.50-2.74)$ & $2.04(1.43-2.91)$ \\
\hline Internal fetal monitoring & $0.86(0.55-1.34)$ & $1.03(0.90-1.18)$ & $1.18(1.01-1.39)$ & $1.31(1.06-1.62)$ & $1.64(1.29-2.10)$ \\
\hline Macrosomia > 4500g & $n a^{\S}$ & $1.33(0.84-2.11)$ & $2.06(1.29-3.31)$ & $3.90(2.36-6.46)$ & $3.53(2.00-6.22)$ \\
\hline SGA & $2.35(1.47-3.76)$ & $0.82(0.67-1.01)$ & $0.68(0.52-0.87)$ & $0.48(0.32-0.71)$ & $0.68(0.45-1.03)$ \\
\hline Prematurity (< 37 weeks) & $2.40(1.32-4.37)$ & $0.76(0.58-1.02)$ & $0.66(0.47-0.95)$ & $1.02(0.68-1.54)$ & $0.71(0.41-1.24)$ \\
\hline
\end{tabular}

na $=$ not applicable. SGA = small for gestational age.

* Odds ratios have been adjusted for parity, insurance class, smoking and maternal age. $†$ The normal $\mathrm{BMI}$ class $\left(18.5-\leqslant 24.9 \mathrm{~kg} / \mathrm{m}^{2}\right) \mathrm{was}$ the reference group for all others.

$\ddagger 75$ th percentile of all maternal lengths of stay. $\$$ Nil in this category. 
considerably higher than reported previously in Australia. Over 65\% of the women in the population studied were overweight or obese, compared with $34 \%$ in Brisbane, in the largest reported Australian cohort, ${ }^{12}$ and $54.7 \%$ in the rural South Australian cohort. ${ }^{5}$ Another Australian multicentre study reported $43 \%$ of nulliparae as overweight or obese, ${ }^{13}$ which is still considerably lower than the $60.5 \%$ overweight and obesity level among nulliparae reported here.

Maternal outcomes in this study are similar to those in previous reports, again highlighting the strong association between excess weight and maternal complications such as diabetes, hypertension and operative delivery. Rural maternity services in many areas are provided by general practitioners, in facilities that may be less well equipped to deal with these complications. This has implications for rural maternity service planning, necessitating appropriate transfer pathways. Further, the doubling of risk of a hospital stay of more than 4 days for obese class III women, consistent with findings in other studies, ${ }^{1,7,12}$ may have implications for health service resourcing, particularly in the context of activity-based funding. This could also affect rural organisations negatively and warrants further assessment.

International and Australian data suggest significant implications of overweight and obesity for perinatal outcomes. $^{12,18}$ If other rural areas have overweight and obesity rates similar to this northern-Victorian population, this is likely to have widespread implications for rural obstetric perinatal mortality rates. It is interesting to note that in Victoria, gestation-standardised data generally show considerably worse perinatal mortality in rural areas than in metropolitan Melbourne. ${ }^{19}$

The excess of overweight and obesity in this report might reflect different ways of measuring BMI compared with other studies. There is a lack of consistency in determining BMI in perinatal research, with many reports using estimated prepregnancy weight, while others, as is the case for GVH, use weight measured during the first antenatal visit. ${ }^{17,11,12,20-22}$ A high percentage of first visits during later gestation could account for variation in some studies, but at GVH, the rates of overweight and obesity for women who presented below 13 weeks' gestation (61\%) and below 20 weeks' gestation $(61.5 \%)$ were similar to those for the whole group (65.6\%). Another potential confounder derives from the role of $\mathrm{GVH}$ as a regional referral facility - smaller facilities may transfer women exceeding various BMI thresholds. The effect of the potential transfer of women from small rural centres to GVH appears to be small as, based on postcode data, almost all women lived locally, and of those transferred from another hospital (274), only 47 had class III obesity.

In this cohort, there appears to be a reduction in preterm delivery and small-for-gestational-age births with increasing BMI. Both of these may be advantageous, as they are linked to perinatal mortality. Meta-analyses have confirmed an increased risk of premature delivery with increasing BMI. ${ }^{23,24}$ The apparent anomaly in the GVH data is likely the result of the transfer, where possible, of women delivering before 32 weeks' gestation to a tertiary centre. Further, although on population graphs there is an apparent reduction in the risk of small-for-gestational-age babies, recent data have confirmed that this effect is lost when using customised growth charts. ${ }^{12}$

The validity of a finding of excess rural pregnancy overweight and obesity is supported by data from a nonobstetric rural population in southwestern Victoria, ${ }^{25}$ which showed that $56.8 \%$ of women between the ages of 25 and 44 were overweight or obese. Thus, the level of maternal obesity in this study appears to truly reflect a concerning difference between this rural cohort and reported urban maternity populations, a finding that, if widespread, has implications for rural maternity services generally and warrants further investigation.

Competing interests: No relevant disclosures.

Received 29 Jun 2012, accepted 25 Sep 2012.

1 Callaway LK, Prins JB, Chang AM, McIntyre HD. The prevalence and impact of overweight and obesity in an Australian obstetric population. Med J Aust 2006; 184 56-59.

2 Doherty DA, Magann EF, Francis J, et al. Pre-pregnancy body mass index and pregnancy outcomes. Int J Gynaecol Obstet 2006; 95: 242-247.

3 GaltierF, Raingeard I, Renard E, et al. Optimizing the outcome of pregnancy in obese women: from pregestational to long-termmanagement. Diabetes Metab 2008: 34: 19-25.
4 Gunatilake RP, Perlow JH. Obesity and pregnancy: clinical management of the obese gravida. Am J Obstet Gynecol 2011; 204:106-119.

5 Dodd JM, Grivell RM, Nguyen AM, et al. Maternal and perinatal health outcomes by body mass index category. Aust N Z J Obstet Gynaecol 2011; 51: 136-140.

6 NohrEA, VaethM, Baker JL, etal.Combined associations of prepregnancy body mass index and gestational weight gain with the outcome of pregnancy. Am J Clin Nutr 2008; 87: 1750-1759.

7 Sebire NJ, Jolly M, Harris JP, et al. Maternal obesity and pregnancy outcome: a study of 287,213 pregnancies in London. Int J Obes Relat Metab Disord 2001; 25: 1775 1182.

8 Fraser RB. Obesity complicating pregnancy.Curr Obstet Gynaecol 2006; 16:295-298.

9 Katz S. Anaesthesia for the obese parturient. O\&G Magazine 2008; 10: 29-31.

10 Cedergren M. Effects of gestational weight gain and body mass index on obstetric outcome in Sweden. Int J Gynaecol Obstet 2006; 93: 269-274.

11 VasudevanC, RenfrewM,McGuireW. Fetal and perinatal consequences of maternal obesity. Arch Dis Child Fetal Neonatal Ed 2011; 96: F378-F382.

12 Mclntyre HD, Gibbons KS, Flenady VJ, Callaway LK. Overweight and obesity in Australian mothers: epidemic or endemic? Med J Aust 2012;196: 184-188.

13 AthukoralaC, Rumbold AR, Willson KJ, CrowtherCA. The risk of adverse pregnancy outcomes in women who are overweight or obese. BMC Pregnancy Childbirth 2010; 10:56.

14 Department of Health. Capability framework for Victorian maternity and newborn services. http:// docs.health.vic.gov.au/docs/doc/Capabilityframework-for-Victorian-maternity-and-newbornservices (accessed Oct 2012).

15 Obesity: preventing and managing the global epidemic Report of a WHO consultation. World Health Organ Tech Rep Ser 2000; 894: i-xii, 1-253.

16 RobertsCL, Lancaster PA. Australian national birthweight percentiles by gestational age. Med J Aust 1999; 170: 114-118.

17 Hoffman L, NolanC, Wilson JD, et al. Gestational diabetes mellitus--management guidelines. The Australasian Diabetes in Pregnancy Society. Med J Aust 1998; 169: 93-97.

18 NohrEA,Bech BH,Davies MJ, etal. Prepregnancy obesity and fetal death: astudy within the Danish National Birth Cohort.Obstet Gynecol 2005; 106: 250-259.

19 Department of Health. Victorian maternity services performance indicators: complete set for 2009-2010. Melbourne: Department of Health, 2012. http:// docs.health.vic.gov.au/docs/doc/NictorianPerformance-Indicators-Report:-Complete-set-for2009-10 (accessed May 2012).

20 BhattacharyaS, Campbell DM, Liston WA, Bhattacharya S. Effect of body mass index on pregnancy outcomes in nulliparous women delivering singleton babies. BMC Public Health 2007; $7: 168$

21 Usha Kiran TS, Hemmadi S, Bethel J, Evans J. Outcome of pregnancy in a woman with an increased body mass index. BJOG 2005; 112: 768-772.

22 Roman H, GoffinetF, Hulsey TF, et al. Maternal body mass index at delivery and risk of caesarean due to dystocia in low risk pregnancies. Acta Obstet Gynecol Scand 2008; 87: 163-170.

23 Torloni MR, Betrán AP, Daher S, et al. Maternal BMl and preterm birth: a systematic review of the literature with meta-analysis. J Matern Fetal Neonatal Med 2009; 22: 957-970.

24 McDonald SD, Han Z, MullaS, Beyene J; Knowledge Synthesis Group. Overweight and obesity in mothers and risk of preterm birth and low birth weight infants: systematic reviewand meta-analyses. BMJ 2010;341: c3428.

25 Janus ED, Laatikainen T, Dunbar JA, et al. Overweight, obesity and metabolic syndrome in rural southeastern Australia. Med J Aust 2007; 187: 147-152. 